\title{
Regime alimentar para ganho compensatório de ovinos em confinamento: composição regional e tecidual da carcaça
}

\author{
[Diet for compensatory gain of feedlot lambs: commercial composition of carcass cuts and tissues] \\ G.H. Nóbrega ${ }^{1}$, M.F. Cézar², J.M. Pereira Filho², W.H. Sousa ${ }^{3}$, O.B. Sousa ${ }^{2}$, \\ M.G.G. Cunha ${ }^{3}$, J.R.S. Santos ${ }^{1}$ \\ ${ }^{1}$ Aluno de pós-graduação - Universidade Federal de Campina Grande - UFCG - Patos, PB \\ ${ }^{2}$ Unidade Acadêmica de Medicina Veterinária - Universidade Federal de Campina Grande - Patos, PB \\ ${ }^{3}$ Pesquisador da EMEPA, PB \\ RESUMO
}

\begin{abstract}
Determinou-se o efeito do regime alimentar para ganho compensatório sobre a composição regional e tecidual da carcaça de cordeiros terminados em confinamento. Foram utilizados 40 ovinos Santa Inês, machos, com média de $17 \pm 1,7 \mathrm{~kg}$ de peso vivo (PV) e 100 dias de idade. Ao final do período de confinamento, os cordeiros foram abatidos, e a meia carcaça esquerda foi seccionada em cinco cortes comerciais primários: pescoço, paleta, costilhar, lombo e perna. A perna foi dissecada em músculos, ossos e gorduras, e, em seguida, teve seu índice de musculosidade determinado. Foi mensurada a hipertrofia muscular por meio da média do diâmetro das fibras musculares. $\mathrm{O}$ peso ( $\mathrm{g}$ ) da meia carcaça esquerda, do pescoço, da paleta, do costilhar, do lombo e da perna diminuiu linearmente, à medida que aumentou o nível de restrição prévia, de $0 \%$ até $60 \%$, variando, respectivamente, de 11497,4 a 8888,5; de 1453,8 a 1211,4 ; de 1955,4 a 1560,9; de 3420,0 a 2604,6; de 1669,4 a 1161,6 e de 2998,8 a 2350,0 . No rendimento dos cortes, apenas o lombo sofreu efeito do regime alimentar, diminuindo de 14,5 para $13,1 \%$. O índice de musculosidade da perna $(0,42$ a 0,39$)$ e o diâmetro das fibras musculares $(46,0$ a 43,4 $\mu \mathrm{m})$ também diminuíram com o aumento da restrição prévia. A restrição alimentar seguida por realimentação diminui o peso dos cortes e não afeta seu rendimento; diminui também a proporção de gordura da carcaça, produzindo, assim, cortes mais leves e carne com menor teor de gordura.
\end{abstract}

Palavras-chave: cortes comerciais, fibra muscular, gordura, músculo, perna

\begin{abstract}
The effect of diets for compensatory gain on the commercial cut yield and carcasses tissue composition of finished feedlot lambs was determined. A total of 40 Santa Inês lambs, with mean body weight (BW) of $17 \pm 1.7 \mathrm{~kg}$ and 100 days old were used. The lambs were slaughtered; the left half carcass was sectioned into five primary commercial cuts: neck, shoulder, rib, loin and leg. The leg was dissected into muscle, bone and fat, and then the muscularity of the leg was determined. Muscle hypertrophy was measured by the mean diameter of muscle fibers. The left half carcass, neck, shoulder, rib, loin and leg weight decreased linearly between 0 and $60 \%$ of previous food restriction levels, ranging, respectively, from 11497.4 to $8888.5 \mathrm{~g}$; from 1453.8 to $1211.4 \mathrm{~g}$; from 1955.4 to $1560.9 \mathrm{~g}$; from 3420.0 to $2604.6 \mathrm{~g}$; from 1669.4 to $1161.6 \mathrm{~g}$ and from 2998.8 to $2350.0 \mathrm{~g}$, as well as loin yield (from 14.5 to $13.1 \%$ ), leg musculosity index (from 0.42 to 0,39) and muscle fiber diameter (from 46.0 to $43.4 \mu \mathrm{m}$ ). Food restriction followed by refeeding promoted decreasing in the weight of cuts and did not affect the yield, and it also decreased the proportion of fat in the carcass, resulting in lighter cuts and leaner meat.
\end{abstract}

Keywords: commercial cuts, fat, leg, muscle, muscle fiber

Recebido em 28 de agosto de 2011

Aceito em 10 de agosto de 2012

E-mail: ghnobrega@hotmail.com 


\section{INTRODUÇÃO}

A espécie ovina contribui no fornecimento de proteína animal à espécie humana. Nesse sentido a produção de carne ovina tem aumentado, e essa pecuária de corte viabiliza a manutenção do pequeno e médio produtor agropecuário, gerando empregos e fixando o trabalhador no meio rural, principalmente no semiárido brasileiro, devido à capacidade de adaptação desses animais às condiçõos climáticas dessa região.

No Nordeste brasileiro, a escassez de alimento em certo período do ano gera irregularidade na oferta do produto, com abate de animais em idade avançada, obtenção de cortes comerciais e, por conseguinte, carne que não mantém os padrões de qualidade, como maciez, cor e suculência (Zeola, 2002). Nesse sentido, Neiva et al. (2005) reportaram que, entre as opções existentes para produzir ovinos durante a seca, época de escassa disponibilidade de forragem, o confinamento surge como alternativa para que a produção seja constante ao longo do ano. Porém, de acordo com Santello et al. (2006), a análise de custos não é favorável ao confinamento.

Algumas tecnologias podem ser utilizadas com o intuito de reduzir tais custos, dentre as quais cabe destaque àquela de submeter os animais confinados ao regime de restrição alimentar seguido de realimentação para se explorar o ganho compensatório. Ben Salem e Smith (2008) afirmaram que a relação custo benefício é um indicador que afeta a adoção dessa técnica pelos ovinocultores. Porém, estudos revelam que o impacto econômico da técnica alivia o impacto da seca no desempenho de pequenos ruminantes.

O ganho compensatório refere-se ao fenômeno manifestado em mamíferos e aves que, após um período de restrição alimentar suficiente para deprimir o crescimento contínuo, ao acabar a restrição e reiniciar uma alimentação adequada, apresentam taxa de crescimento acima do normal, em animais da mesma idade e tamanho e em condições similares de ambiente (Ben Salem e Smith, 2008). Um dos principais fatores a ser considerado no confinamento e no ganho compensatório é o potencial de desempenho dos animais a serem confinados e compensados, de forma que os mesmos devem responder aos ganhos esperados em função da dieta oferecida. O rebanho ovino nordestino é composto em sua vasta maioria por animais nativos deslanados e semilanados, dos quais cabe destaque ao Santa Inês, por ser numericamente expressivo e pelo seu grande potencial para produção de carne (Sousa et al., 2003); fato que legitima a utilização dessa raça para se verificar os efeitos do regime alimentar para o ganho compensatório.

A quantidade da porção comestível de uma carcaça pode ser estimada através da avaliação de sua composição regional e tecidual. A composição regional de uma carcaça é dada pela proporção dos diferentes cortes comerciais obtidos desta. Tal proporção é influenciada por uma série de fatores, concernentes ao animal e ao meio ao qual ele está inserido, sendo que idade, peso, raça e dieta são os que mais a afetam. Os cortes comerciais podem ser classificados como de primeira (perna e lombo), segunda (costilhar e paleta) e terceira categoria (pescoço). Então, o que se espera de uma boa carcaça é que tenha o máximo rendimento em cortes de primeira categoria.

O método considerado mais preciso para a estimativa da composição tecidual é a dissecação de toda a carcaça em três principais grupos de tecidos, ou seja, ósseo, muscular e adiposo, e a determinação de sua proporção. Porém, a dissecação de apenas um dos lados ou de um corte representativo da carcaça também pode ser utilizada com sucesso para essa determinação. A paleta e a perna são os cortes mais utilizados para predizer a composição tecidual da carcaça, pois são considerados bons indicadores da sua proporção de osso, músculo e gordura. Levandose em conta que o músculo é o componente mais nobre da porção comestível, e que a fibra muscular é seu principal constituinte, a hipertrofia dessa fibra vem sendo apontada como indicador de alterações que podem promover diferenças em parâmetros de qualidade da carcaça, conforme trabalhos realizados por Choi e Kim (2009); Hwang et al. (2010) e Lee et al. (2010).

Com ênfase nos pontos acima expostos, objetivou-se com este trabalho determinar o efeito do regime alimentar para ganho compensatório sobre características quantitativas da carcaça de cordeiros terminados em confinamento, por meio da sua composição regional e tecidual, além da hipertrofia das fibras do músculo semimembranoso. 


\section{MATERIAL E MÉTODOS}

Para a realização do experimento, foram utilizados 40 ovinos Santa Inês, machos inteiros, desmamados, com média de $17 \pm 1,7 \mathrm{~kg}$ de peso vivo (PV) e 100 dias de idade. No início do experimento, os animais, identificados, foram alojados em baias individuais com dimensões de $1,0 \times 1,2 \mathrm{~m}$, alocadas em galpão com piso de cimento e coberto com telhas de barro, equipadas com comedouros e bebedouros.

Os animais eram alimentados duas vezes ao dia, às 7 e às 15 horas. A dieta experimental (Tab. 1), na forma de ração completa, foi formulada com base nas exigências dos animais para ganho de $250 \mathrm{~g}$ por dia, segundo as recomendações do NRC (National..., 1985).

Tabela 1. Proporção dos ingredientes e composição bromatológica da ração experimental

\begin{tabular}{|c|c|}
\hline Ingrediente & Proporção (\%) \\
\hline Feno de tifton & 30,0 \\
\hline Milho moído & 47,0 \\
\hline Farelo de soja & 16,5 \\
\hline Farelo de trigo & 4,0 \\
\hline Calcário & 1,5 \\
\hline Sal mineral & 1,0 \\
\hline \multicolumn{2}{|l|}{ Composição bromatológica } \\
\hline Matéria seca & 90,07 \\
\hline Proteína bruta ${ }^{1}$ & 16,25 \\
\hline Extrato etéreo $^{1}$ & 3,17 \\
\hline Energia metabolizável (Mcal/kg de MS) ${ }^{2}$ & 2,82 \\
\hline Fibra em detergente neutro ${ }^{1}$ & 63,84 \\
\hline Matéria mineral $^{1}$ & 6,14 \\
\hline
\end{tabular}

A fase de campo do experimento teve duração de 98 dias, entre os meses de janeiro e abril, incluindo 14 dias iniciais de adaptação dos animais às instalações, ao manejo e à dieta. $\mathrm{O}$ restante foi dividido em dois períodos distintos: um de restrição alimentar, de 42 dias (primeiro ao $42^{\circ}$ dia) e um de realimentação, também de 42 dias $\left(43^{\circ}\right.$ ao $84^{\circ}$ dia). No período de restrição alimentar, os animais, divididos em quatro tratamentos, receberam $0,20,40$ e $60 \%$ de restrição, em que os do tratamento $0 \%$ recebiam alimentação à vontade, com reajuste diário que permitia sobra de 10\%, garantindo assim o consumo voluntário, e os demais tratamentos seguiram o regime de restrição alimentar de 20 , 40 e $60 \%$ em relação ao tratamento sem restrição. No período de realimentação, todos os animais, de todos os tratamentos, foram realimentados sem restrição, ou seja, à vontade.

Ao final do período de confinamento, os cordeiros foram submetidos a jejum de 16 horas de dieta hídrica e 24 horas de dieta sólida, sendo em seguida pesados para obtenção do peso vivo ao abate. Os animais foram abatidos seguindo técnicas e normas preconizadas pelo RIISPOA
(Brasil, 1997). Após resfriamento, em câmara frigorífica com temperatura inferior a $4^{\circ} \mathrm{C}$ por 24 horas, as carcaças foram divididas, simétrica e longitudinalmente, em duas meias-carcaças, esquerda e direita. A meia carcaça esquerda foi seccionada em cinco cortes comerciais primários, como se segue: pescoço, paleta, costilhar, lombo e perna. A perna foi congelada para posterior dissecação.

Para a determinação da composição tecidual da perna, o corte foi descongelado, pesado e dissecado, para separação e quantificação da proporção de seus diferentes tecidos, quais sejam: músculos, ossos e gorduras, segundo metodologia descrita por Cezar e Sousa (2007). Em seguida, somando-se o peso dos cinco músculos que envolvem o fêmur (PM), ou seja, glúteo bíceps (Biceps femoris), semimembranoso (Semimembranosus), semitendinoso (Semitendinosus), quadríceps femural (Quadriceps femoris) e adutor (Adductor), e relacionando a referida soma com o comprimento do fêmur $(\mathrm{CF})$, por meio da 
fórmula $\mathrm{IMP}=\frac{\sqrt{\mathrm{PM} / \mathrm{CF}}}{\mathrm{CF}}$, foi determinado o índice de musculosidade da perna (Purchas et al., 1991).

A obtenção dos fragmentos musculares para a avaliação da hipertrofia foi realizada imediatamente após o abate, para evitar alterações pós-morte no material. Coletaram-se amostras do músculo semimembranoso, as quais foram fixadas em formol tamponado por 24 horas. Após a fixação, as peças eram lavadas em água corrente e mantidas em álcool $70 \%$ até o momento do processamento histológico para inclusão em parafina. Fragmentos teciduais de 3 $\mathrm{mm}$ de espessura foram desidratados em concentrações crescentes de álcool (70 a 100\%), diafanizados em xilol e em seguida incluídos em parafina a $58-60^{\circ} \mathrm{C}$. Os blocos de parafina foram levados ao micrótomo rotativo (Leica RM 2125rt) para a obtenção de cortes histológicos com $5 \mu \mathrm{m}$ de espessura. Em seguida os cortes foram corados pela técnica de HematoxilinaEosina (HE), e as lâminas, montadas com lamínula sobre entellan, conforme Samuelson (2007).

Determinou-se o grau de hipertrofia muscular pela média dos diâmetros das fibras musculares $(\mu \mathrm{m})$, de acordo com Dubowitz e Brooke (1973), por meio da mensuração de 150 fibras musculares, seccionadas transversalmente, por animal. Os cortes foram totalmente rastreados, e as secções celulares, medidas aleatoriamente e de forma sequenciada, para evitar o reexame de uma mesma área do corte. A captação das imagens e a morfometria das fibras de tecido muscular foi feita por meio do software computacional ImagePro Express 6.0, acoplado a um microscópio de bancada, Olympus BX41, utilizando objetiva de $40 x$.

O delineamento experimental utilizado foi o inteiramente casualizado, com quatro tratamentos (considerando as dietas do período de restrição - 0, 20, 40 e 60\%) e dez repetições. As análises estatísticas foram realizadas através de análise de variância e de regressão, segundo os procedimentos PROC GLM e PROC REG do SAS (Statistical..., 1999).

\section{RESULTADOS E DISCUSSÃO}

Os cordeiros foram abatidos com média de idade de aproximadamente 190 dias e pesos variando de 42,68 a 34,70kg, do menor para o maior nível de restrição prévia. Considerando o período experimental total (84 dias), as variáveis peso reconstituído da $1 / 2$ carcaça esquerda $(\mathrm{g})$ e o peso dos cortes $(\mathrm{g})$ diminuíram linearmente, à medida que aumentou o nível de restrição prévia (Tab. 2). Sendo assim, entende-se que, no período de realimentação, o ganho de peso não foi suficiente para compensar a perda ocorrida durante a fase de restrição prévia, ou seja, não houve ganho compensatório para essas variáveis.

Vários fatores podem influenciar o ganho compensatório; entre eles, o grau de maturidade em que se encontram os animais (Almeida et al., 2011), além da severidade e duração da restrição (Homem Junior et al., 2007). Esses mesmos autores indicaram que a restrição alimentar prévia de $30 \%$, seguida de realimentação, pode ser adotada como prática de manejo nutricional, mas restrições mais severas, como a de $60 \%$, não são recomendadas, pois podem prejudicar o desempenho dos animais - fatos que puderam ser claramente observados nos animais deste experimento, em que os da restrição prévia de $20 \%$ atingiram pesos, de meia carcaça e de cortes, próximos aos animais sem restrição prévia, enquanto os com $60 \%$ foram menores (Tab. 2).

Considerando o peso dos cortes comerciais dos animais submetidos à restrição prévia de $60 \%$, estes obtiveram maiores pesos, quando comparados aos atingidos por cordeiros Santa Inês em pastejo, recebendo suplementação concentrada ( $1,5 \%$ do peso vivo), com peso médio de abate de $27,09 \mathrm{~kg}$, que foram de $1816,50 \mathrm{~g}, \quad 553,25 \mathrm{~g}, \quad 1077,00 \mathrm{~g}, \quad 435,25 \mathrm{~g}$ e $1422,50 \mathrm{~g}$, para perna, lombo, paleta, pescoço e costilhar, respectivamente (Dantas et al., 2008). Tal fato indica que, mesmo nos animais que tiveram menores pesos dos cortes, o confinamento com regime alimentar de restrição seguida de realimentação proporciona bons pesos de cortes comerciais. 
Tabela 2. Peso reconstituído da meia carcaça esquerda (g) e peso (g) e rendimento (\%) dos cortes comerciais de cordeiros Santa Inês submetidos à restrição e realimentação, terminados em confinamento

\begin{tabular}{lccccc} 
Variável & $0 \%$ & $20 \%$ & $40 \%$ & $60 \%$ & $\mathrm{P}$ \\
\hline 1/2 carcaça, g & $11497,40 \pm 1261,92$ & $10513,60 \pm 960,99$ & $10278,60 \pm 803,21$ & $8888,50 \pm 755,66$ & $<0,01^{1}$ \\
Perna, g & $2998,80 \pm 396,06$ & $2731,40 \pm 263,12$ & $2826,40 \pm 412,89$ & $2350,00 \pm 219,79$ & $<0,01^{2}$ \\
Lombo, g & $1669,40 \pm 241,74$ & $1440,40 \pm 153,67$ & $1345,20 \pm 111,15$ & $1161,60 \pm 110,55$ & $<0,01^{3}$ \\
Paleta, g & $1955,40 \pm 204,98$ & $1817,40 \pm 134,08$ & $1799,40 \pm 128,91$ & $1560,90 \pm 127,86$ & $<0,01^{4}$ \\
Pescoço, g & $1453,80 \pm 178,95$ & $1313,20 \pm 165,10$ & $1344,80 \pm 194,80$ & $1211,40 \pm 183,00$ & $<0,01^{5}$ \\
Costilhar, g & $3420,00 \pm 537,29$ & $3211,20 \pm 446,73$ & $2962,80 \pm 354,75$ & $2604,60 \pm 410,84$ & $<0,01^{6}$ \\
Perna, \% & $26,07 \pm 1,61$ & $26,01 \pm 1,47$ & $27,43 \pm 2,62$ & $26,45 \pm 1,21$ & $\mathrm{~ns}$ \\
Lombo, \% & $14,48 \pm 0,82$ & $13,70 \pm 0,83$ & $13,11 \pm 0,90$ & $13,07 \pm 0,64$ & $<0,01^{7}$ \\
Paleta, \% & $17,04 \pm 1,08$ & $17,34 \pm 1,19$ & $17,54 \pm 0,95$ & $17,61 \pm 1,23$ & $\mathrm{~ns}$ \\
Pescoço, \% & $12,80 \pm 2,06$ & $12,50 \pm 1,04$ & $13,15 \pm 2,11$ & $13,70 \pm 2,01$ & $\mathrm{~ns}$ \\
Costilhar, \% & $29,64 \pm 1,88$ & $30,46 \pm 2,18$ & $28,80 \pm 2,11$ & $29,21 \pm 3,01$ & $\mathrm{~ns}$ \\
\hline
\end{tabular}

${ }^{1} \mathrm{y}=11504,0-40,3 \mathrm{x} \quad\left(\mathrm{r}^{2}=0,48\right) ; \quad{ }^{2} \mathrm{y}=3004,4-9,3 \mathrm{x} \quad\left(\mathrm{r}^{2}=0,27\right) ; \quad{ }^{3} \mathrm{y}=1646,9-8,1 \mathrm{x} \quad\left(\mathrm{r}^{2}=0,57\right) ; \quad{ }^{4} \mathrm{y}=1963,5-6,0 \mathrm{x}$ $\left(r^{2}=0,44\right) ;{ }^{5} y=1435,1-3,5 x\left(r^{2}=0,16\right) ;{ }^{6} y=3453,8-13,5 x\left(r^{2}=0,34\right) ;{ }^{7} y=14,3-0,02 x\left(r^{2}=0,32\right)$.

Ainda na Tabela 2, observa-se que, no rendimento dos cortes comerciais (\%), à exceção do lombo, que também diminuiu com o aumento da restrição prévia, não houve efeito do regime alimentar, ou seja, apesar das diferenças entre os pesos, a maioria dos cortes não mostrou diferenças em suas proporções.

Os rendimentos dos cortes dos animais deste experimento foram próximos aos obtidos por Araújo Filho et al. (2010), em pesquisa com cordeiros Santa Inês confinados, que atingiram proporções de $31,8 \%$ de perna, $14,2 \%$ de lombo, $18,2 \%$ de paleta, $7,9 \%$ de pescoço e $27,9 \%$ de costela. Perna e costilhar, classificados como cortes de primeira e segunda, respectivamente, foram os que atingiram maior proporção na meia carcaça, com médias de $26,5 \%$ e $29,5 \%$, na mesma ordem; por outro lado, o pescoço, corte de terceira, teve a menor proporção, $13,0 \%$. Tais resultados podem atribuir a essas carcaças, mesmo a de menor tamanho $(60 \%$ de restrição prévia), um adequado valor comercial, pois, de acordo com Cézar e Souza (2010), a proporção dos diferentes cortes na carcaça se constitui em um importante fator na determinação do seu valor comercial. Sendo assim, quanto maior a proporção dos cortes de primeira, e menor dos cortes de terceira, melhor será esse valor.

A proporção do lombo, em relação à meia carcaça, diminuiu à medida que aumentou a restrição prévia. Isso confirma a afirmativa de
Araújo Filho et al. (2010), de que dietas com menor densidade energética proporcionam menor velocidade no desenvolvimento dos tecidos e, sendo o lombo o corte de desenvolvimento mais tardio na carcaça ovina (Moreno et al., 2010), este foi o mais afetado pelo manejo alimentar imposto aos cordeiros.

A composição tecidual da perna é de grande importância na avaliação da qualidade da carcaça, pois apresenta altos índices de correlação, quanto às suas proporções de músculo, osso e gordura, com a carcaça inteira de ovinos (Cézar e Sousa, 2010). O peso reconstituído da perna (g) e os pesos de músculos, ossos e gorduras (g) diminuíram linearmente, à medida que aumentou o nível de restrição prévia (Tab. 3 ).

Os pesos da perna, assim como dos tecidos (músculo, osso e gordura), dos animais deste experimento se aproximam dos pesos obtidos por cordeiros Santa Inês, confinados por 45 dias, estudados por Furusho-Garcia et al. (2003), que foram de $2526 \mathrm{~g}$ para a perna, $1677 \mathrm{~g}$ de músculo, $365 \mathrm{~g}$ de osso e $484 \mathrm{~g}$ de gordura. Assim como no peso dos cortes, o período de realimentação não foi suficiente para compensar a perda ocorrida na fase de restrição prévia, o que nos permite dizer que o sistema de alimentação influencia o peso absoluto dos tecidos que compõem as carcaças dos cordeiros. 
Tabela 3. Peso reconstituído da perna $(\mathrm{g})$, peso $(\mathrm{g})$ e rendimento $(\%)$ dos músculos, ossos e gordura, musculosidade da perna e diâmetro $(\mu \mathrm{m})$ de fibras musculares do músculo semimembranoso de cordeiros Santa Inês submetidos à restrição e realimentação, terminados em confinamento

\begin{tabular}{|c|c|c|c|c|c|}
\hline Variável & $0 \%$ & $20 \%$ & $40 \%$ & $60 \%$ & $\mathrm{P}$ \\
\hline Perna, $\mathrm{g}$ & $2870,15 \pm 386,19$ & $2567,78 \pm 263,29$ & $2625,99 \pm 231,52$ & $2238,95 \pm 202,42$ & $<0,01^{1}$ \\
\hline Músculos, g & $1944,38 \pm 240,39$ & $1782,09 \pm 209,30$ & $1855,85 \pm 190,38$ & $1555,92 \pm 174,90$ & $<0,01^{2}$ \\
\hline Ossos, $\mathrm{g}$ & $559,59 \pm 98,21$ & $504,12 \pm 80,78$ & $516,78 \pm 56,16$ & $475,74 \pm 50,51$ & $<0,05^{3}$ \\
\hline Gorduras, $\mathrm{g}$ & $366,17 \pm 85,83$ & $281,57 \pm 55,85$ & $253,36 \pm 43,01$ & $207,29 \pm 41,79$ & $<0,01^{4}$ \\
\hline Músculos, \% & $67,89 \pm 3,15$ & $69,33 \pm 2,34$ & $70,60 \pm 2,17$ & $69,30 \pm 2,29$ & ns \\
\hline Ossos, \% & $19,44 \pm 1,58$ & $19,56 \pm 1,61$ & $19,73 \pm 1,83$ & $21,31 \pm 1,98$ & $<0,05^{5}$ \\
\hline Gorduras, \% & $12,68 \pm 2,08$ & $11,11 \pm 2,74$ & $9,67 \pm 1,50$ & $9,30 \pm 1,91$ & $<0,01^{6}$ \\
\hline $\mathrm{RMO}^{10}$ & $3,52 \pm 0,43$ & $3,57 \pm 0,33$ & $3,61 \pm 0,41$ & $3,29 \pm 0,42$ & ns \\
\hline $\mathrm{RMG}^{11}$ & $5,53 \pm 1,21$ & $6,60 \pm 1,68$ & $7,49 \pm 1,40$ & $7,80 \pm 1,89$ & $<0,01^{7}$ \\
\hline $\mathrm{IMP}^{12}$ & $0,42 \pm 0,02$ & $0,40 \pm 0,02$ & $0,41 \pm 0,03$ & $0,39 \pm 0,02$ & $<0,01^{8}$ \\
\hline $\operatorname{DFM}^{13}(\mu \mathrm{m})$ & $46,01 \pm 1,59$ & $45,36 \pm 1,32$ & $44,61 \pm 2,22$ & $43,35 \pm 2,00$ & $<0,01^{9}$ \\
\hline \multicolumn{6}{|c|}{$\begin{array}{l}\mathrm{y}=2851,0246-9,1769 \mathrm{x}\left(\mathrm{r}^{2}=0,35\right) ;{ }^{2} \mathrm{y}=1948,3073-5,4582 \mathrm{x}\left(\mathrm{r}^{2}=0,25\right) ;{ }^{3} \mathrm{y}=549,8945-1,1945 \mathrm{x}\left(\mathrm{r}^{2}=0,12\right) ;{ }^{4} \mathrm{y}=352,8228- \\
2,5242 \mathrm{x}\left(\mathrm{r}^{2}=0,49\right) ;{ }^{5} \mathrm{y}=19,1398+0,0289 \mathrm{x}\left(\mathrm{r}^{2}=0,12\right) ;{ }^{6} \mathrm{y}=12,4262-0,0579 \mathrm{x} \quad\left(\mathrm{r}^{2}=0,29\right) ;{ }^{7} \mathrm{y}=5,7003+0,0385 \mathrm{x} \quad\left(\mathrm{r}^{2}=0,25\right) ; \\
8 \mathrm{y}=0,4180-0,0004 \mathrm{x}\left(\mathrm{r}^{2}=0,18\right),{ }^{9} \mathrm{y}=46,1388-0,0437 \mathrm{x}\left(\mathrm{r}^{2}=0,24\right) ;{ }^{10} \text { relação músculo:osso; }{ }^{11} \text { relação músculo:gordura; } \\
{ }^{12} \text { índice de musculosidade da perna; }{ }^{13} \text { diâmetro da fibra muscular. }\end{array}$} \\
\hline
\end{tabular}

Não houve influência do regime alimentar para a variável rendimento de músculos (\%), entretanto o rendimento de ossos (\%) aumentou, enquanto o rendimento de gorduras $(\%)$ diminuiu, à medida que aumentou o nível de restrição prévia (Tab. 3).

Considerando os rendimentos do tratamento de maior restrição prévia (60\%), estes são próximos aos obtidos em cordeiros Santa Inês confinados, estudados por Almeida et al. (2009), que foram em média de $65,47 \%$ de músculos, $25,14 \%$ de ossos e 9,39\% de gorduras. Esses autores concluíram que o nível de consumo de energia metabolizável afeta a proporção de gordura e ossos na carcaça, ou seja, um menor consumo de energia diminui a proporção de gordura e aumenta a proporção de ossos. Tal afirmativa explica os resultados deste experimento para o rendimento desses tecidos, pois, sendo o adiposo de crescimento mais tardio, a realimentação não proporcionou o mesmo acúmulo de gordura nos animais que sofreram restrição prévia, diminuindo sua proporção em relação ao tecido ósseo.

A relação músculo:osso não sofreu influência do regime alimentar, no entanto a relação músculo:gordura aumentou, enquanto o índice de musculosidade da perna e o diâmetro das fibras musculares $(\mu \mathrm{m})$ diminuíram linearmente, em relação ao aumento do nível de restrição prévia.
Quanto maiores as relações músculo:osso e músculo:gordura, maior a musculosidade e menor a adiposidade da carcaça, respectivamente, ou seja, maior será o rendimento da porção comestível (Cézar e Sousa, 2010). As carcaças obtidas neste experimento apresentaram média de relação músculo:osso de 3,50 e uma variação da relação músculo:gordura de 5,53 a 7,80, ambas um pouco menores que as obtidas por Cunha et al. (2008) para cordeiros Santa Inês em confinamento, que foram em média de 5,49 e 9,64, respectivamente. Isso permite concluir que as carcaças obtidas neste experimento, independentemente do nível de restrição, têm boas musculosidade e adiposidade, pois apresentam relações satisfatórias entre músculo, osso e gordura.

Quanto maior o índice de musculosidade da perna, maior a proporção de carne na carcaça. O índice observado neste trabalho diminuiu de 0,42 a 0,39, números que podem ser considerados próximos aos obtidos por Moreno et al. (2010), trabalhando com ovinos Ile de France $(0,47)$, raça considerada pelos autores como de maior aptidão para produção de carne do que a Santa Inês. A musculosidade da perna pode variar em decorrência de fatores genéticos e ambientais, idade, raça, peso corporal e dieta (Purchas et al., 1991), o que pode explicar a variação observada no presente trabalho.

O crescimento do tecido muscular é caracterizado, até o momento antes do 
nascimento, pelo aumento do número de fibras e, após o nascimento, pelo aumento do tamanho dessas fibras (Rosa et al., 2002), que podem variar de 10 a $100 \mu \mathrm{m}$ de diâmetro (Lee et al., 2010). O diâmetro de fibras observado neste trabalho variou de 46,01 a 43,35 $\mu \mathrm{m}$, sendo maior que o observado por Santello et al. (2009), em cordeiras Dorset x Santa Inês com média de peso de abate de $30 \mathrm{~kg}$, com uma média de $35,10 \mu \mathrm{m}$, diferença que pode ser atribuída ao maior peso de abate dos animais deste experimento.

O índice de musculosidade da perna e o diâmetro da fibra muscular, observados neste trabalho, tiveram o mesmo comportamento, ou seja, ambos diminuíram em ritmos semelhantes, com decréscimos de $7,1 \%$ e 5,8\%, respectivamente, em relação ao aumento da restrição prévia. Isso sugere a existência de uma relação entre $o$ diâmetro da fibra muscular e a musculosidade da carcaça, isto é, quanto maior esse diâmetro, maior a proporção de carne na carcaça.

\section{CONCLUSÃO}

A restrição alimentar seguida por realimentação diminui o peso dos cortes e não afeta seu rendimento. Diminui também a proporção de gordura da carcaça, produzindo, assim, cortes mais leves e carne com menor teor de gordura.

\section{REFERÊNCIAS}

ALMEIDA, T.R.V.; PEREZ, J.R.O.; CHLAD, M. et al. Desempenho e tamanho de vísceras de cordeiros Santa Inês após ganho Compensatório. Rev. Bras. Zootec., v.40, p.616-621, 2011.

ALMEIDA, T.R.V.; PÉREZ, J.R.O.; PAULA, O.J. et al. Efeito do nível de energia metabolizável na composição dos tecidos da carcaça de cordeiros da raça Santa Inês. Arq. Bras. Med. Vet. Zootec., v.61, p.1364-1372, 2009.

ARAÚJO FILHO, J.T.; COSTA, R.G.; FRAGA, A.B. et al. Desempenho e composição da carcaça de cordeiros deslanados terminados em confinamento com diferentes dietas. Rev. Bras. Zootec., v.39, p.363-371, 2010.
BEN SALEM, H.; SMITH, T. Feeding strategies to increase small ruminant production in dry environments. Small Rumin. Res., v.77, p.174194, 2008.

BORBUREMA, J.B. Desempenho e perfil metabólico de ovinos Santa Inês submetidos ao regime alimentar para crescimento compensatório em confinamento. 2010. 56f. Dissertação (Mestrado em Medicina Veterinária) - Centro de Saúde e Tecnologia Rural, Universidade Federal de Campina Grande, Patos, PB.

BRASIL. MINISTÉRIO DA AGRICULTURA. Regulamento da Inspeção Industrial e Sanitária de Produtos de Origem Animal. Brasília, DF: MA, 1997.

CEZAR, M.F.; SOUSA, W.H. Carcaças ovinas e caprinas: obtenção, avaliação, classificação. Uberaba-MG: Ed. Agropecuária tropical, 2007. $147 \mathrm{p}$.

CEZAR, M.F.; SOUSA, W.H. Proposta de avaliação e classificação de carcaças de ovinos deslanados e caprinos. Tecnol. Cienc. Agropec., v.4, p.41-51, 2010.

CHOI, Y.M.; KIM, B.C. Muscle fiber characteristics, myofibrillar protein isoforms, and meat quality. Liv. Sci., v.122, p.105-118, 2009.

CUNHA, M.G.G.; CARVALHO, F.F.R.; GONZAGA NETO, S. et al. Características quantitativas de carcaça de ovinos Santa Inês confinados alimentados com rações contendo diferentes níveis de caroço de algodão integral. Rev. Bras. Zootec., v.37, p.1112-1120, 2008.

DANTAS, A.F.; PEREIRA FILHO, J.M.; SILVA, A.M.A. et al. Características da carcaça de ovinos Santa Inês terminados em pastejo e submetidos a diferentes níveis de suplementação. Ciênc. Agrotec., v.32, p.1280-1286, 2008.

DUBOWITZ, V.; BROOKE, M. Muscle biopsy: a modern approch. London: Sunders, 1973. 475p.

FURUSHO-GARCIA， I.F.; PEREZ， J.R.O.; TEIXEIRA, J.C. Componentes de carcaça e composição de alguns cortes de cordeiros Texel x Bergamácia, Texel x Santa Inês e Santa Inês puros, terminados em confinamento, com casca de café como parte da dieta. Rev. Bras. Zootec., v.32, p.1999-2006, 2003 (Supl. 2). 
HOMEM JUNIOR, A.C.; SILVA SOBRINHO, A.G.; YAMAMOTO, S.M. et al. Ganho compensatório em cordeiras na fase de recria: desempenho e medidas biométricas. Rev. Bras. Zootec., v.36, p.111-119, 2007.

HWANG, Y.H.; KIM, G.D.; JEONG, J.Y. et al. The relationship between muscle fiber characteristics and meat quality traits of highly marbled Hanwoo (Korean native cattle) steers. Meat Sci., v.86, p.456-461, 2010.

LEE, S.H.; JOO, S.T.; RYU, Y.C. Skeletal muscle fiber type and myofibrillar proteins in relation to meat quality. Meat $S c i$., v.86, p.166170,2010 .

MORENO, G.M.B.; SOBRINHO, A.G.S.; LEÃO, A.G. et al. Rendimentos de carcaça, composição tecidual e musculosidade da perna de cordeiros alimentados com silagem de milho ou cana-de-açúcar em dois níveis de concentrado. Arq. Bras. Med. Vet. Zootec., v.62, p.686-695, 2010.

NATIONAL RESEARCH COUNCIL - NRC. Nutrient requeriments of sheep. 6.ed. Washington, D.C.: National Academy Press, 1985. 99p.

NATIONAL RESEARCH COUNCIL - NRC. Nutrient requirements of small ruminants: sheep, goats, cervids, and new world camelids. Washington, D.C.: The National Academies Press, 2007. 347p.

NEIVA, J.N.M.; SOARES, A.N.; MORAES, S.A. et al. Farelo de glúten de milho em dietas para ovinos em confinamento. Rev. Ciênc. Agron., v.36, p.111-117, 2005.
PURCHAS, R.W.; DAVIES, A.S.; ABDUKKAH, A.Y. An objective measure of muscularity: changes with animal growth and differences between genetic lives of south down sheep. Meat Sci., v.30, p.81-94, 1991.

ROSA, G.T.; PIRES, C.C.; SILVA, J.H.S. et al. Crescimento de osso, músculo e gordura dos cortes da carcaça de cordeiros e cordeiras em diferentes métodos de alimentação. Rev. Bras. Zootec., v.31, p.2283-2289, 2002.

SAMUELSON, D.A. Tratado de Histologia Veterinária. Rio de Janeiro: Elsevier, 2007. $527 \mathrm{p}$.

SANTELLO, G.A.; MACEDO, F.A.F.; DIAS, F.J. et al. Desempenho e características histoquímicas do tecido muscular esquelético de cordeiras terminadas em diferentes sistemas. Acta. Sci. Anim. Sci, v.31, p.425-431, 2009.

SANTELLO, G.A.; MACEDO, F.A.F.; MEXIA, A.A. et al. Características de carcaça e análise do custo de sistemas de produção de cordeiros $1 / 2$ Dorset Santa Inês. Rev. Bras. Zootec., v.35, p.1852-1859, 2006 (Supl. 2).

SOUSA, W.H.; LÔBO, R.N.B.; MORAIS, O.R. Ovinos Santa Inês: Estado da Arte e Perspectivas. In: SIMPÓSIO INTERNACIONAL SOBRE CAPRINOS E OVINOS DE CORTE, 2., 2003, João Pessoa. Anais... João Pessoa: EmepaPB, 2003. p.501-522.

STATISTICAL analisys system. SAS user's guide: statistics. Versão 5. Cary: SAS, 1999.

ZEOLA, N.M.B.L. Conceitos e parâmetros utilizados na avaliação da qualidade da carne ovina. Rev. Nac. Carne, v.26, p.36-56, 2002. 